\title{
Assessment the capacity utilization of mature and immature area of replanting using time driven activity-based costing
}

\author{
S.N.A.M. Zaini1.* and M.Y. Abu ${ }^{1}$ \\ ${ }^{1}$ Faculty of Manufacturing and Mechatronic Engineering Technology, Universiti Malaysia Pahang, 26600 Pahang, Malaysia.
}

\begin{abstract}
Malaysia is currently the world's largest exporter of palm oil although it is the secondlargest producer of the oil after neighboring Indonesia. There have recently been few concerns on this plantation. There are difficulties to understand the variance in the operations, the rate setting is inadequate to outlined the relation between the resources supplied and the capacity in operation, and finally the manager has no system to track the used and unused capacity. The aim of this work is to assess the capacity utilization of mature and immature area at replanting for a better accuracy. Time-driven activity-based costs (TDABC) is used because time efficiency can be calculated effectively. Furthermore, it also can precisely evaluate idle capacity and separately listing the resources being used and not used. This work considers a data in 2017 to develop the solution. This work found that in the mature area from the available capacity utilization, chipping has high insufficient capacity with RM-1931518.08, planting seedlings has high insufficient capacity with 805173.84 minutes and internal transport has high waste cost with RM45771.30. Meanwhile, in the immature area, planting seedlings has high insufficient capacity with 566934.84 minutes and RM-1621433.64, manuring has unused capacity with 66763.50 minutes and internal transport has high waste cost with RM29667.47.
\end{abstract}

\section{ARTICLE HISTORY}

Revised: 29th August 2020

Accepted: $30^{\text {th }}$ September 2020

\section{KEYWORDS}

\section{replanting}

palm oil plantation

time-driven activity-based costing

capacity cost rate

time equation

\section{INTRODUCTION}

Palm oil is one of the world's primary oil origins from some of the 17 main fats and oils. The industry contributes greatly to the Gross Domestic Product (GDP), which in 2018 garners an export revenue of RM 68.49 billion and which is one of the pillars of the Malaysian economy [1]. The wide variety of uses of palm oil and palm oil in food items and non - food items have developed their diverse range throughout the region. The advancement in the worldwide economy has led to international challenges for sustainable management in different aspects of the production and consumption patterns [2]. Abdullah et al., [3] suggested that high management, quality assurance and organizational skills are very relevant in sustainable green practices services. Somehow it was introduced caused by a lack of financial awareness and an incorrect cost structure. Until the 80s, conventional standard cost structures were much less beneficial as the product's direct labor content declined.

Activity-based costing (ABC) is a costing technique developed by Cooper and Kaplan who claimed that many products perform the same process and need different amounts of resources [4]. For each of the activities involved they received specific financial data and cost drivers and subsequently enhanced the profitability of the company [5]. The approach of this method concentrated also on the costs of manufacturing, supplying or endorsing goods based on activity [6]. This method is ideal for the industry that frequently manufactures batches of items [7].

TDABC, however, is a revised $\mathrm{ABC}$, which applies the resource costs from the cost objects directly through the capacity cost rate. This methodology's basic concept is that costs drivers are translated into time equations, which shows time needed in order to carry out a particular task [8]. Information of time utilization is important in order to assess the capacity utilization accurately. In the automotive sector, Ghani et al., [9] claimed that an excess capacity station and multiple underused capacity stations offer a clear idea of the company's management for better investment strategies. Zamrud et al., [10] has shown that the company has been equipped with details about production costs and time utilization, and seems to have a potential in practising TDABC to increase the accuracy in deciding the appropriate method for each of the products. Through evaluating the magnetic component from Kamil et al., [11], the manufacturing cost of the winding toroid core and the remaining capacity which able to increase the time efficiency has been confirmed to be -RM 2967504.12 and -889200.12 minutes respectively. So Safeiee et al., [12] suggested that TDABC is recognized as the most comprehensive and accurate calculation method for the use of resources utilization and unused capacity. 


\section{RESEARCH METHODOLOGY AND RESULTS}

The TDABC is applied by several stages. All activities and sub-activities are defined using process mapping and any resources documented. The time equation is then formed by classifying the driver of costs directly proportional to the costs of the operations. The capacity cost rate is determined through an estimate of all the cost of capacities delivered and the capacity presently being used in the production process. Eventually, the forecast is made through the evaluation of unused capacity in time and cost. This work is conducted at the plantation located in Muadzam Shah, Pahang and considered mature and immature areas in replanting center which consists of seven activities namely chipping, road and drain constructions, planting seedlings, manuring, field maintenance, harvesting and internal transport. The immature area is where all plants where up to 2 to 3 years after planting, before harvestable production begins and when the canopy is not yet closed. Whereas the mature area is locating 4 to 25 years old plants. The estimated capacity required by each activity was determined by quantifying the frequency of the activity in a month. By multiplying the amount of a given activity by the time spent doing it, one could calculate the total time spent on the activity. The volumes of cost-drivers for the activity centers are shown in Table 1.

Table 1. Volume of cost-drivers for the replanting.

\begin{tabular}{|c|c|c|c|}
\hline Var. & Driver & $\begin{array}{r}\text { Quantity/month } \\
\text { (mature) }\end{array}$ & $\begin{array}{r}\text { Quantity/month } \\
\text { (immature) }\end{array}$ \\
\hline & Chipping & & \\
\hline $\mathrm{X}_{1}$ & Felling and shredding (amount of palms) & 46356.00 & 32730.00 \\
\hline \multirow[t]{2}{*}{$\mathrm{X}_{2}$} & Tillage (rounds) & 200.00 & 200.00 \\
\hline & Road and drain constructions & & \\
\hline$X_{3}$ & Road construction (rounds) & 200.00 & 200.00 \\
\hline $\mathrm{X}_{4}$ & Terrace construction (rounds) & 200.00 & 200.00 \\
\hline$X_{5}$ & Chamber/platform construction (rounds) & 200.00 & 200.00 \\
\hline $\mathrm{X}_{6}$ & Drains construction (rounds) & 200.00 & 200.00 \\
\hline $\mathrm{X}_{7}$ & Soil and water conservation (rounds) & 200.00 & 200.00 \\
\hline $\mathrm{X}_{8}$ & Lining (amount of palms) & 46356.00 & 32730.00 \\
\hline \multirow[t]{2}{*}{$\mathrm{X}_{9}$} & Holing (rounds) & 46356.00 & 32730.00 \\
\hline & Planting & & \\
\hline $\mathrm{X}_{10}$ & Legume cover crop (rounds) & 0.08 & 0.08 \\
\hline $\mathrm{X}_{11}$ & Transportation and distribution of seedlings (rounds) & 92712.00 & 65460.00 \\
\hline $\mathrm{X}_{12}$ & Planting seedlings (amount of palms) & 92712.00 & 65460.00 \\
\hline \multirow[t]{2}{*}{$\mathrm{X}_{13}$} & EFB Mulching (amount of palms) & 92712.00 & 65460.00 \\
\hline & Manuring & & \\
\hline \multirow[t]{2}{*}{$X_{14}$} & Manuring programme (amount of palms) & 46356.00 & 32730.00 \\
\hline & Field maintenance & & \\
\hline $\mathrm{X}_{15}$ & Pruning (rounds) & 0.08 & 0.08 \\
\hline $\mathrm{X}_{16}$ & Weeding (rounds) & 1.50 & 1.50 \\
\hline \multirow[t]{2}{*}{$\mathrm{X}_{17}$} & Pest and disease control (rounds) & 3.25 & 3.25 \\
\hline & Harvesting & & \\
\hline $\mathrm{X}_{18}$ & Harvesting fresh fruit bunch (FFB) (amount of palms) & 92712.00 & 65460.00 \\
\hline $\mathrm{X}_{19}$ & $\begin{array}{l}\text { Collect all bunches and loose fruits into wheelbarrow } \\
\text { (amount of palms) }\end{array}$ & 92712.00 & 65460.00 \\
\hline \multirow[t]{2}{*}{$X_{20}$} & Manually loading FFB to truck bin (amount of palms) & 92712.00 & 65460.00 \\
\hline & Internal transportation & & \\
\hline$X_{21}$ & Transport FFB from field to ramp & 193.15 & 136.38 \\
\hline
\end{tabular}

A time equation is needed to be developed to calculate the estimated used time. Each estimated time taken for subactivities are same for both mature and immature areas. TDABC time equation is able to incorporate all the time needed to undertake all sub-activities in each activity center within a single equation as shown in Table 2.

Table 2. Time equations for replanting

\begin{tabular}{clll}
\hline No & Activities & Area & Time Equations \\
\hline 1. & Chipping & Mature & $4 \mathrm{X}_{1}+480 \mathrm{X}_{2}$ \\
& & Immature & $4 \mathrm{X}_{1}+480 \mathrm{X}_{2}$ \\
2. & Road and drain constructions & Mature & $480 \mathrm{X}_{3}+480 \mathrm{X}_{4}+480 \mathrm{X}_{5}+480 \mathrm{X}_{6}+480 \mathrm{X}_{7}+4 \mathrm{X}_{8}+\mathrm{X}_{9}$ \\
& & Immature & $480 \mathrm{X}_{3}+480 \mathrm{X}_{4}+480 \mathrm{X}_{5}+480 \mathrm{X}_{6}+480 \mathrm{X}_{7}+4 \mathrm{X}_{8}+\mathrm{X}_{9}$ \\
3. & Planting & Mature & $480 \mathrm{X}_{10}+0.75 \mathrm{X}_{11}+8 \mathrm{X}_{12}+2 \mathrm{X}_{13}$ \\
& & Immature & $480 \mathrm{X}_{10}+0.75 \mathrm{X}_{11}+8 \mathrm{X}_{12}+2 \mathrm{X}_{13}$ \\
4. & Manuring & Mature & $0.083 \mathrm{X}_{14}$ \\
\hline
\end{tabular}




\begin{tabular}{|c|c|c|c|}
\hline & & Immature & $0.05 X_{14}$ \\
\hline \multirow[t]{2}{*}{5.} & Field maintenance & Mature & $46356 X_{15}+46356 X_{16}+40601 X_{17}$ \\
\hline & & Immature & $19638 X_{15}+19638 X_{16}+40601 X_{17}$ \\
\hline \multirow[t]{2}{*}{6.} & Harvesting & Mature & $3 X_{18}+2 X_{19}+X_{20}$ \\
\hline & & Immature & $2 X_{18}+2 X_{19}+X_{20}$ \\
\hline \multirow[t]{2}{*}{7.} & Internal transportation & Mature & $15 X_{21}$ \\
\hline & & Immature & $15 X_{21}$ \\
\hline
\end{tabular}

In Table 3, it shows on how to get the actual used capacity for sub-activities in all activity centers by multiplying the value of quantity or round needed for sub-activities per month with total time taken for every round. For mature area, the highest total used capacity is planting with $996693.84 \mathrm{~min} / \mathrm{month}$ while for immature area is also planting with 703734.84 $\mathrm{min} / \mathrm{month}$. The actual time spent (used capacity) in replanting for mature area is 2758208.84 minutes and in immature area is 2068286.64 minutes.

Table 3. Total used time for sub-activities of replanting

\begin{tabular}{lrrrrrr}
\hline \multirow{2}{*}{ Area } & \multicolumn{2}{c}{ Quantity/month } & \multicolumn{2}{c}{ Minute/round } & \multicolumn{2}{c}{ Used capacity (min/month) } \\
\cline { 2 - 7 } & Mature & Immature & Mature & Immature & Mature & Immature \\
\hline Chipping & 46556.00 & 32930.00 & 484.00 & 484.00 & 281424.00 & 226920.00 \\
\hline Road and drain constructions & 93712.00 & 66460.00 & 2405.00 & 2405.00 & 711780.00 & 643650.00 \\
\hline Planting & 278136.08 & 196380.08 & 490.75 & 490.75 & 996693.84 & 703734.84 \\
\hline Manuring & 46356.00 & 32730.00 & 0.08 & 0.05 & 3847.55 & 1636.50 \\
\hline Field maintenance & 4.83 & 4.83 & 133313.00 & 79877.00 & 205294.20 & 162999.60 \\
\hline Harvesting & 278136.00 & 196380.00 & 6.00 & 5.00 & 556272.00 & 327300.00 \\
\hline Internal transportation & 193.15 & 136.38 & 15.00 & 15.00 & 2897.25 & 2045.70 \\
\hline TOTAL: & 743094.07 & 525021.30 & 136713.83 & 83276.80 & 2758208.84 & 2068286.64 \\
\hline
\end{tabular}

For the practical capacity, working hours of employees are been estimated. In this plantation, the working hours are Monday to Saturday, 8 a.m. to 6 p.m. and on Sunday from 8 a.m. to 1 p.m. The employees work an average of eight hours a day for Monday to Saturday basis (26 days a month) and five hours on Sunday (4 days a month). Based on the scheduled working hours, the employees have an acceptable capacity of 13,680 minutes each per month. Estimated costs of all the resources used in the sub-activities are summarized in Table 4.

Table 4. Labor, equipment, machinery and other equipment costs within the replanting

\begin{tabular}{lrrrrrr}
\hline \multirow{2}{*}{ Area } & \multicolumn{2}{c}{ Labor costs } & \multicolumn{2}{c}{ Overheads } & \multicolumn{2}{c}{$\begin{array}{c}\text { Oost all resources } \\
\text { supplied }\end{array}$} \\
\cline { 2 - 8 } & Mature & Immature & Mature & Immature & Mature & Immature \\
\cline { 2 - 8 } Chipping & 5200.00 & 3900.00 & 461195.84 & 325630.77 & 466395.84 & 329530.77 \\
\hline Road and drain constructions & 20800.00 & 15600.00 & 450209.46 & 317873.76 & 471009.46 & 333473.76 \\
\hline Planting & 18200.00 & 13000.00 & 306675.85 & 378776.77 & 324875.85 & 391776.77 \\
\hline Manuring & 6500.00 & 6500.00 & 23270.71 & 20936.29 & 29770.71 & 27436.29 \\
\hline Field maintenance & 14036.34 & 9449.60 & 55318.16 & 39057.80 & 69354.50 & 48507.40 \\
\hline Harvesting & 35100.00 & 25350.00 & 5400 & 4200.00 & 40500.00 & 29550.00 \\
\hline Internal transportation & 9271.20 & 6546.00 & 40175.20 & 28366.00 & 49446.40 & 34912.00 \\
\hline Total: & 109107.54 & 80345.60 & 1342245.22 & 1114841.39 & 1451352.76 & 1195186.99 \\
\hline
\end{tabular}

Based on the same approach, the total costs of utilization for each of the sub-activities in the replanting is shown in Table 5 .

Table 5. Total production costs for replanting

\begin{tabular}{|c|c|c|c|c|c|c|}
\hline \multirow[t]{2}{*}{ Activities } & \multicolumn{2}{|c|}{$\begin{array}{l}\text { Used capacity } \\
\text { (min) }\end{array}$} & \multicolumn{2}{|c|}{ Capacity cost rate (RM/min) } & \multicolumn{2}{|c|}{$\begin{array}{c}\text { Total cost } \\
\text { (RM/month) }\end{array}$} \\
\hline & Mature & Immature & Mature & Immature & Mature & Immature \\
\hline Chipping & 281424.00 & 226920.00 & 8.52 & 8.03 & 2397732.48 & 1822167.60 \\
\hline Road and drain constructions & 711780.00 & 643650.00 & 2.15 & 2.03 & 1530327.00 & 1306609.50 \\
\hline Planting & 996693.84 & 703734.84 & 1.70 & 2.86 & 1694379.53 & 2012681.64 \\
\hline Manuring & 3847.55 & 1636.50 & 0.44 & 0.40 & 1692.92 & 654.60 \\
\hline Field maintenance & 205294.20 & 162999.60 & 0.56 & 0.59 & 114964.75 & 259169.37 \\
\hline Harvesting & 556272 & 327300.00 & 0.16 & 0.17 & 89003.52 & 55641.00 \\
\hline Internal transportation & 2897.25 & 2045.70 & 1.20 & 2.55 & 3476.70 & 5216.54 \\
\hline Total: & 2758208.84 & 2068286.64 & & & 5831576.90 & 5462140.25 \\
\hline
\end{tabular}




\section{DISCUSSION}

Figure 1, 2, 3 and 4 shows the used capacity, unused capacity, utilization cost and waste cost respectively for chipping, road and drain constructions, planting, manuring, field maintenance, harvesting and internal transportation in both mature and immature areas. Based on Figure 1, the used capacity in mature area shows higher value of usage compared to immature area. Planting process have the highest used capacity which are 996693.84 minutes and 703734.84 minutes for mature and immature area separately.

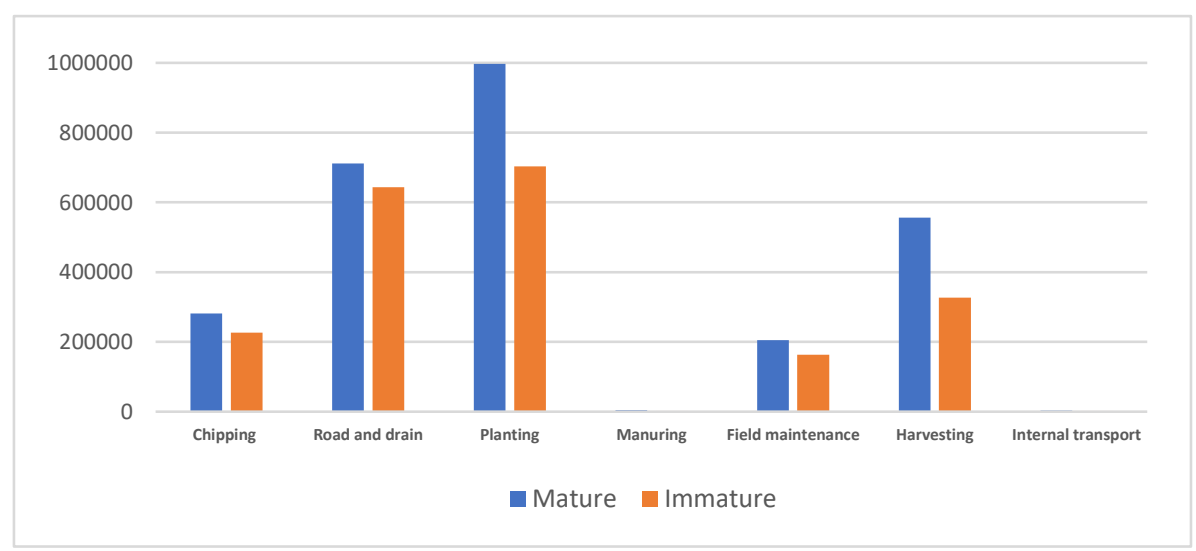

Figure 1. Used capacity

In Figure 2, it shows that only sub-activity harvesting in immature area, manuring and internal transportation in both areas have unused capacity. The other five sub-activities experienced insufficient capacity due to low number of manpower. Planting process in mature area have the highest insufficient capacity which is 805173.84 minutes. Whereas manuring in immature area have the highest insufficient capacity with 66763.50 minutes.

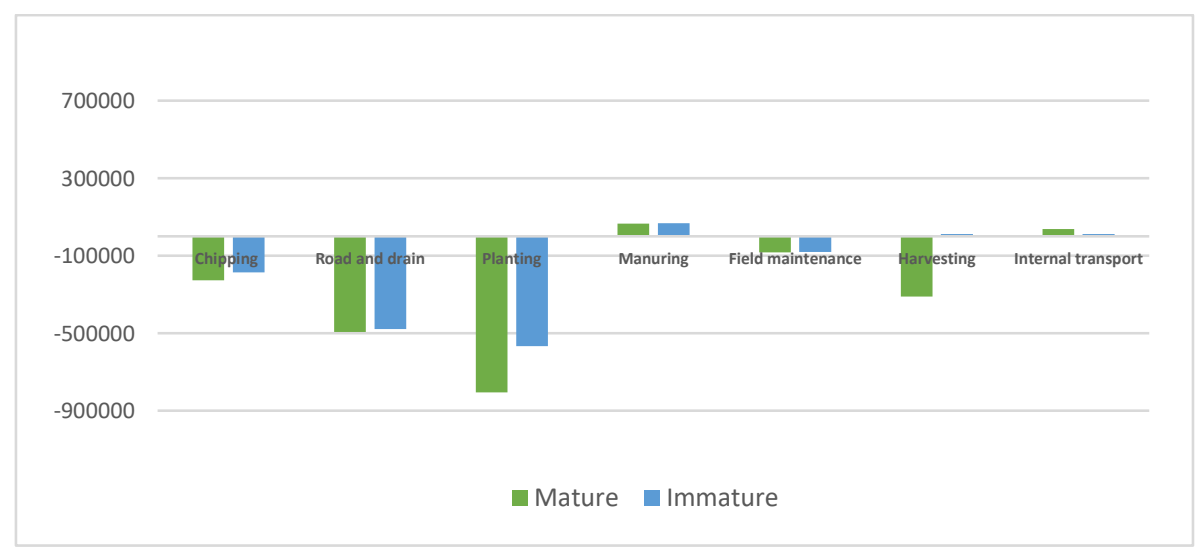

Figure 2. Unused capacity

The used capacity will affecting the value of utilization cost which portrays in Figure 3. The CCR for every subactivities are different, so the rate to identify the utilization cost will be unlike. For an example, the used capacity of chipping in mature area is not the highest, but it have the highest value of utilization cost which is RM 2397732.48 due to its big CCR value, 8.52 .

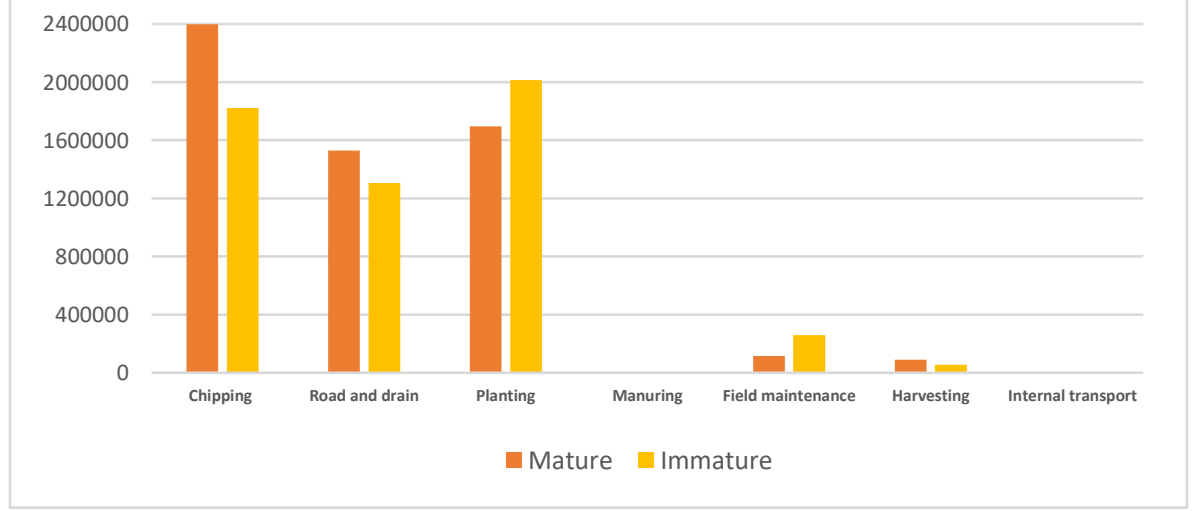

Figure 3. Utilization cost 
Moreover, the unused capacity will have an impact on the value of waste cost which displays in Figure 4 . Based on the identical point of view from utilization cost, the rate to measure the waste cost will be different separately because the CCR for every sub-activities are different. In planting, although the insufficient capacity in mature area is larger than in immature area, but the total waste cost in mature area is lower than in immature area. This is because the CCR are 1.70 in mature area and 2.86 in immature area respectively.

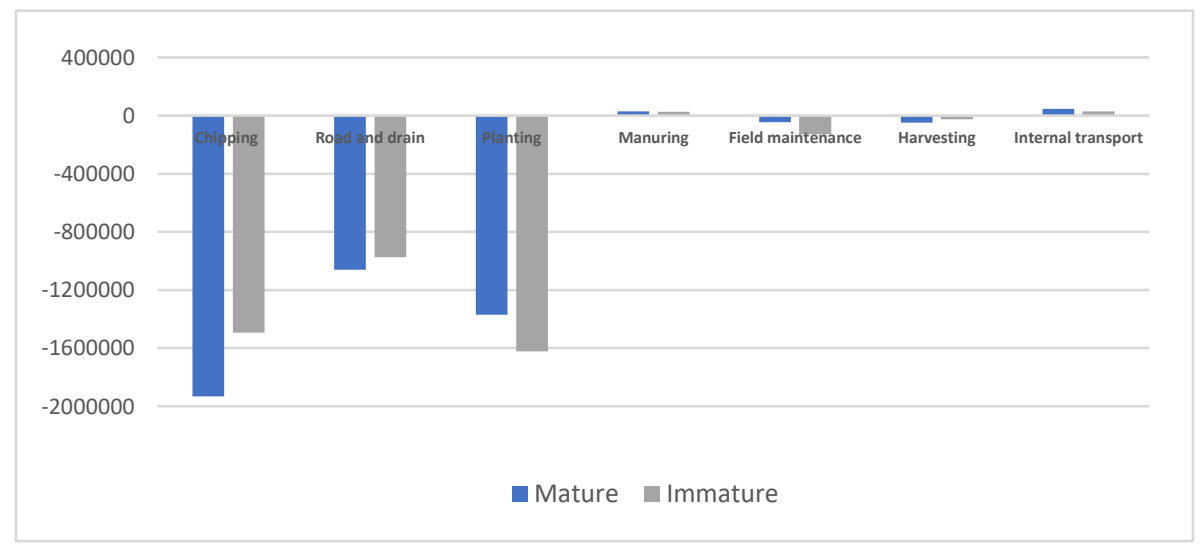

Figure 4. Waste cost

\section{CONCLUSION}

Overall, this work managed to establish the time equation, capacity cost rate, used and unused capacity of replanting center in palm oil plantations for mature and immature areas. The manager thus has a strong perspective on lessening the cost of production by assessing capacity usage to generate a high efficiency of working capacity and reduce cost of waste.

\section{ACKNOWLEDGEMENT}

This research is fully supported by RDU1903105 and the authors fully acknowledge University Malaysia Pahang for the approved fund which makes this research effective.

\section{REFERENCES}

[1] "DOSM", Department of Statistics Malaysia, Putrajaya., 2019

[2] J.V. Geibler, "Market-based Governance for Sustainability in Value Chains: Conditions for Successful Standard Setting in the Palm Oil Sector," J. Cleaner Production, vol 56, pp. 39-53, 2013.

[3] M.A. Abdullah, B. C. Chew, and S. R. Hamid, "The Sustainable Service Management Factors in High Technology Transport Service Industry", Journal of Advanced Manufacturing Technology, pp. 101-113, 2017.

[4] R. Cooper, and R. S. Kaplan, "Profit Priorities from Activity-based Costing", Harv Bus Rev., vol. 6, no. 91, pp. 30-135, 1991.

[5] S. N. A. M. Zaini, C. W. Zheng, and M. Y. Abu, "Costing Structure Improvement using Activity based Costing in Palm Oil Plantation of Malaysia", Journal of Modern Manufacturing Systems and Technology, vol. 4, no. 1, pp. 95-109, 2020.

[6] N. F. Zamrud, and M. Y. Abu, "Comparative Study: Activity based Costing and Time Driven Activity based Costing in Electronic Industry", Journal of Modern Manufacturing Systems and Technology, vol 4, no. 1, pp. 68-81, 2020.

[7] N. F. Zamrud, M. Y. Abu, N. N. N. M. Kamil, and F. I. M. Safeiee, "A Comparative Study of Product Costing by using Activity-Based Costing (ABC) and Time-Driven Activity-Based Costing (TDABC) Method", International Manufacturing Engineering Conference \& The Asia Pacific Conference on Manufacturing Systems, pp. 171-178, 2020.

[8] G. Keel, C. Savage, M. Rafiq, and P. Mazzocato, "Time-Driven Activity-based Costing in Health Care: A Systematic Review of the Literature", Health Policy, vol. 121, no. 7, pp. 755-763, 2017.

[9] N. F. A. Ghani, S. N. A. M. Zaini, and M. Y. Abu, "Assessment the Unused Capacity using Time Driven Activity based Costing in Automotive Manufacturing Industry", Journal of Modern Manufacturing Systems and Technology. vol. 4, no. 1, pp. 82-94, 2020.

[10] N. F. Zamrud, M. Y. Abu, N. N. N. M. Kamil, and F. L. M. Safeiee, "The Impact of Capacity Cost Rate and Time Equation of Time-Driven Activity-based Costing (TDABC) on Electric Component", International Manufacturing Engineering Conference \& The Asia Pacific Conference on Manufacturing Systems, pp. 81-87, 2020.

[11] N. N. N. M. Kamil, M. Y. Abu, N. F. Zamrud, and F. L. M. Safeiee, "Analysis of Magnetic Component Manufacturing Cost through the Application of Time-Driven Activity-Based Costing", International Manufacturing Engineering Conference \& The Asia Pacific Conference on Manufacturing Systems, pp. 74-80, 2020.

[12] F. L. M. Safeiee, M. Y. Abu, N. N. N. M. Kamil, and N. F. Zamrud, "The Application of Time-Driven Activity based Costing System on Inductors in Electrics and Electronics Industry", International Manufacturing Engineering Conference \& The Asia Pacific Conference on Manufacturing Systems. pp. 88-95, 2020. 